\title{
Carbon nanotubes cement composites
}

\author{
Giuseppe Ferro \\ Politecnico di Torino, Department of Structural Engineering and Geotechnics, 10129 Torino, Italy
}

Jean-Marc Tulliani

Politecnico di Torino, Department of Materials Science and Chemical Engineering, 10129 Torino, Italy

Simone Musso

Department of Physics, Politecnico di Torino, 10129 Torino, Italy

MIT - Department of Civil and Environmental Engineering, Cambridge, MA, 02139, USA

ABSTRACT. The present paper reviews the current state of the art of carbon nanotubes cement-based composites and the possible applications. The influence of carbon nanotubes additions onto cement paste mechanical and electrical properties are discussed in detail. Though promising, several challenges have still to be solved before the introduction of these new materials into the public sphere through civil infrastructures.

KeYwords. Cement; Mortars; Hydration; Carbon nanotubes; Mechanical properties; Electrical properties.

\section{INTRODUCTION}

$\mathrm{C}$ arbon nanotubes (CNTs) are hollow tubular channels, formed either by one wall (SWCNTs, Fig. 1a) or several walls (MWCNTs, Fig. 1b), of rolled graphene sheets [1], having diameters ranging between 0.4 and $10 \mathrm{~nm}$ for SWCNTs or from 4 to $100 \mathrm{~nm}$ for MWCNTs. CNTs length is not restricted and can reach micro or even millimeter range. CNTs are not produced, however, by rolling up graphite sheets, but rather by a growth process from one end: the synthesis of SWNTs is achieved under precisely controlled conditions in the presence of a catalyst; in case of the deviation from the production route, multi-wall carbon nanotubes (MWNTs) are formed.

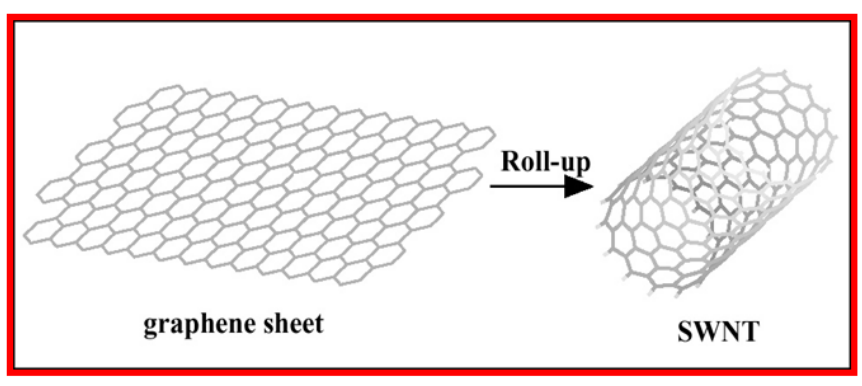

(a)

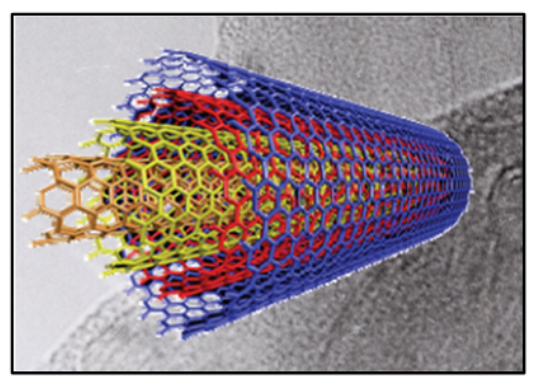

(b)

Figure 1: Illustration of SWCNTs (a) and MWCNTs (b).

The research on CNT composites has initially focused on polymer matrices, with ceramics and metals also being considered for this role. While initial results were generally disappointing, often showing little or no improvement in 
composite properties over traditional reinforcing materials, more recent results have been much more promising, showing significant improvements in fracture toughness, hardness and strength in both ceramic and polymer matrices. Key factors that have contributed to these improvements include the process of distributing the CNT in the matrix material and the degree of bonding between the reinforcement and the matrix. Traditional reinforcing mechanisms such as crack bridging, fiber pull out and crack deflection have been identified in ceramic matrices, with additional, nanoscale reinforcement mechanisms also being seen [2].

Concrete is the most widely used construction material (more than 11 billion metric tons are consumed every year all over the world and the cement industry is responsible for approximately 5-8\% worldwide of all anthropogenic emissions of carbon dioxide [3]) and has experienced the developing stages of normal strength concrete, high strength concrete and high performance concrete. Nowadays, the investigation of the properties of this material in the nanometric and micrometric scale range constitutes a major focus of the research, as the comprehension of these characteristics enables the understanding and the control of its macroscopic properties [4].

On the other hand, carbon nanotubes have many advantageous mechanical and electrical properties such as high strength, high conductivity and, therefore, are attractive for producing fiber-reinforced concrete. It is expected that carbon nanotubes, when added to concrete, will increase compression strength beyond $200 \mathrm{MPa}$, thus allowing the construction of mile-high skyscrapers. [5]. Moreover, the incorporation of fibers at the nanoscale will allow the control of the matrix cracks at the nanoscale level, owing, thus to increase its toughness. High performance concrete also allows a reduction of raw materials consumption, because it is then possible to achieve a specific strength with less material, and, as a consequence, to reduce energy consumption and to minimize $\mathrm{CO}_{2}$ emissions $\left(\mathrm{CO}_{2}\right.$ emission scales with $\mathrm{L}^{3}$ (volume), while structural strength scales with section S (columns) and $\mathrm{S} 1.5$ (beams)).

Generally, since aggregates occupy about $60-70 \%$ or more of the volume of a concrete mix, the possibility to use aggregates from construction demolition is also beneficial for reducing $\mathrm{CO}_{2}$ emissions. Concrete production from recycled aggregates is mandatory to solve the problem of waste land-filling too: in Italy, in 2004 , wastes from construction demolition were equal to $800 \mathrm{~kg}$ per person, which signals a need for reuse to protect the environment. In particular, recycling of concrete blocks, which make up to $37 \%$ of construction waste, is an important issue to be promoted [6]. However, the incorporation of $30 \%$ of recycled aggregates into a new concrete leads to a significant reduction of the mechanical properties, thus CNTs additions can compensate for this strength loss. To conclude, nanotechnology is able to help in producing a sustainable concrete.

Mechanically, CNTs show elastic behavior, with a Young's Modulus of approximately $1 \mathrm{TPa}$ and a density of about 1.33 $\mathrm{g} / \mathrm{cm}^{3}$. Single walled CNTs have yield stresses between 20 and $60 \mathrm{GPa}$, with measured yield strains of up to 10\% [2]. Moreover, carbon nanotubes can bear torsion and bending without breaking. Since CNTs exhibit great mechanical properties along with extremely high aspect ratios (length-to-diameter ratio) ranging from 30 to more than many thousands, they are expected to produce significantly stronger and tougher cement composites than traditional reinforcing materials (e.g. glass fibers or carbon fibers). In fact, because of their size (ranging from $1 \mathrm{~nm}$ to tens of nm) and aspect ratios, CNTs can be distributed in a much finer scale than common fibers, giving as a result a more efficient crack bridging at the very preliminary stage of crack propagation within composites [2] (Fig. 2).

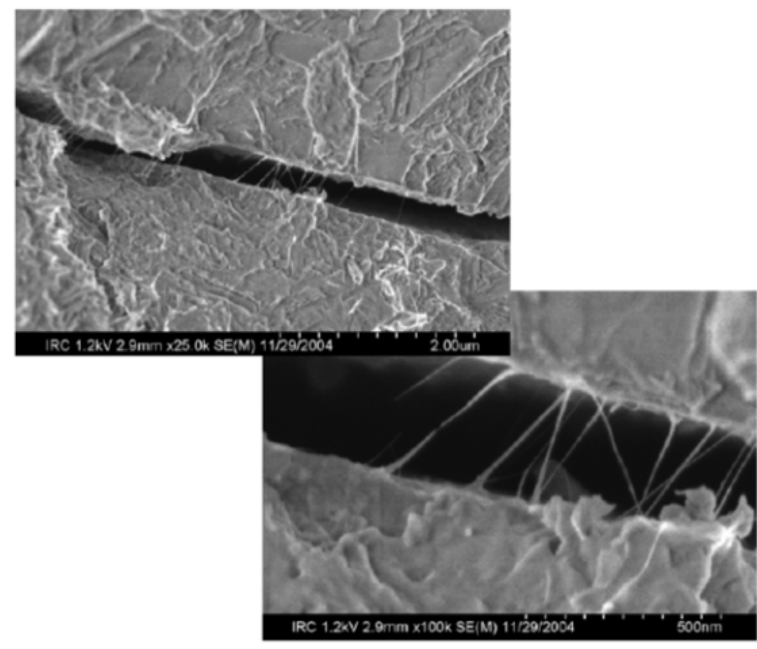

Figure 2: Crack bridging effect in cement/CNTs composites [2]. 
However, properties and dimensions of CNTs strongly depend on the deposition parameters and the nature of the synthesis method. In view of a commercial application, the chemical vapor deposition (CVD) technique is the only one that can offer a path towards low-cost and large scale production, albeit it must be highlighted that CVD can produce nanotubes that have non negligible amount of lattice defects along the graphene walls and often these tubes are curled and aggregated to form bundles and ropes (Fig. 3) that have a lower strength and are very difficult to disperse [7].

The amount of defects can play a key role for cement reinforcement application. In fact, defect free CNTs, obtained with a complete graphitization process achieved by heat-treatment at high temperature [8], either in vacuum or inert environment, show outstanding mechanical properties [9], although they are incapable to form proper adhesion with the matrix, causing what it is called sliding [6]. On the other hand, while lattice defects limit mechanical strength, they are reactive spots that can be used to produce functional groups on the outer walls by chemical treatments with acid solutions. These superficial chemical groups, such as carboxylic $(-\mathrm{COOH})$ groups, can originate strong chemical bonds between CNTs and cementitious matrix, thus enhancing the reinforcement efficiency even though to the detriment of graphitization degree $[11,12,13]$. Furthermore, chemical treatments can help to disentangle the bundles, hence facilitating a uniform dispersion at the single tube level, above all in aqueous media such as that for cement composites.

Proper dispersion and adequate load transfer are the main challenges in the search for efficient carbon nanotubes reinforced cement composites.

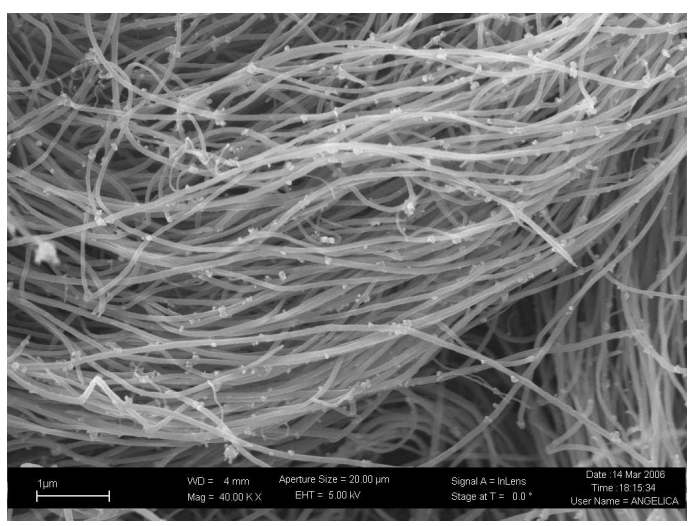

Figure 3: Scanning electron microscopy (SEM) micrograph of a bundle of MWCNTs produced by CVD technique from camphor and ferrocene.

Depending on their precise structure, CNTs may be metallic or semiconductors: It is known that the electronic properties of CNTs can be controlled by chemical modifications of outer surface or by the presence, in the surrounding atmosphere or inside poorly degassed nanotubes, of minute quantities of $\mathrm{O}_{2}$. In particular, the conductivity type of the CNT can be changed from $\mathrm{p}$-type to n-type by adsorption of $\mathrm{O}_{2}$ [14].

Normal concrete is not sensitive to applied loads because of its low electrical conductivity. This weakness can be overcome by adding carbon nanotubes, which have a high conductivity $\left(10^{2}-10^{4} \mathrm{~S} / \mathrm{cm}\right)$. Therefore, if concrete is submitted to compressive forces this will increase the number of contact points between the nanotubes and thus, will lead to a decrease in the resistance of the material. This will then confer to concrete a stress-sensitivity that will enable a stress monitoring of the structures through the measurement of the variations of electrical resistivity. This feature of the carbon nanotubes reinforced structures will be used to continuously monitor normal stresses during service life as well as, exceptional events such as seism, shocks and explosions that generate plastic deformations [15]. Experimental results [16] showed that the fabricated self-sensing $\mathrm{CNT} /$ cement composites present sensitive and stable responses to repeated compressive loadings and impulsive loadings, and also have remarkable responses to vehicular loadings. These findings indicate that self-sensing $\mathrm{CNT} /$ cement composites have great potential for traffic monitoring.

\section{CNTS DISPERSION}

7 he dispersion of carbon nanotubes in the matrix is complex given the widespread specific surface area of the nanoparticles and due to Van der Waals forces which tend to favor the formation of agglomerates. Different techniques for dispersing said materials in solvents (acetone, ethanol...) in addition to ultrasounds, mechanical 
shaking or a combination of the two techniques, have already been tried out [18]. Moreover, as such CNTs are hydrophobic.

Commercial single walled carbon nanotubes dispersed by sonication in isopropanol with ordinary Portland cement $(0.02$ by weight $\mathrm{CNT} /$ cement ratio) for four hours led to cement particles coated with bundles of carbon nanotubes after alcohol evaporation [2]. After hydration (with a 0.4 water to cement ratio (w/c) and use of $10 \mathrm{~g} / \mathrm{L}$ of a superplasticizer), CNT bundles were smaller in apparent diameter and more widely distributed with respect to unhydrated cement. However, the CNTs directly affected the early hydration process, producing higher hydration rates than those experienced by control samples, as evidenced from hardness tests and SEM observations [19-21].

Common superplasticizer, Mapei Dynamon SP1, an admixture based on modified acrylic polymer for precast concrete proved also to be effective in MWCNTs dispersion into water, after 4 hours of sonication by means of an ultrasonic probe [13, 22] (Fig. 4).

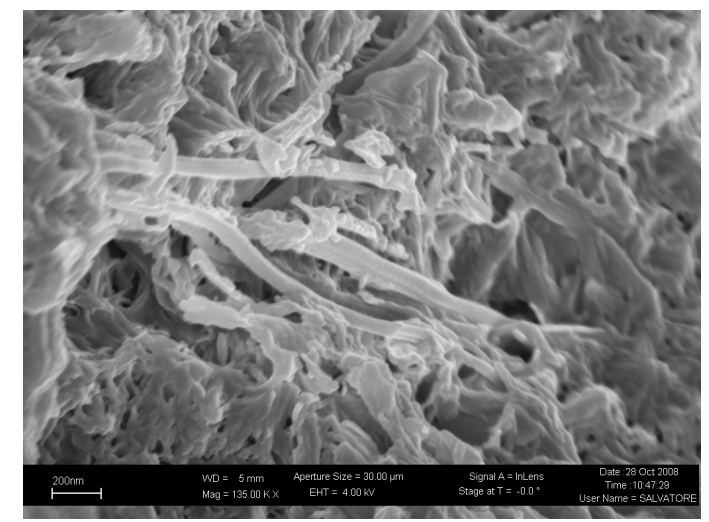

Figure 4: SEM micrograph of $0.5 \mathrm{wt} \%$ MWCNT cement composite [17].

Recent experiments have confirmed that MWCNTs can be effectively dispersed in the mixing water by using a simple, one step method utilizing ultrasonic energy and a commercially available surfactant [19]. Shah et al. [24] have evidenced that in the samples where no dispersing technique was used, CNTs appeared poorly dispersed forming large agglomerates and bundles. On the other hand, as expected, in the samples where dispersion was achieved by applying ultrasonic energy and using a surfactant, only individual CNT were identified on the fracture surface. As a result of effective dispersion, the mechanical properties of cement matrices, studied using fracture mechanics three-point bending tests on notched specimens, were substantially increased by adding a very low amount of CNT, $0.025 \%$ to $0.08 \%$ by mass of cement. The use of CNT at this very low percentage makes the cost of the material very attractive. This small quantity also enables the control of matrix cracks at the nanoscale level, as shown by scanning electron microscopy results. It was found that in addition to reinforcement benefits, CNTs can also improve the transport properties of cementitious materials by increasing the early age strain capacity of the cementitious matrix [25] and the incorporation of CNTs has led to a substantial reduction of the autogenous shrinkage [24].

\section{FUNCTIONALIZATION}

S amples having up to $10 \mathrm{wt} \%$ of as such MWCNTs (Tab. 1) were prepared by Tulliani et al [26] (Fig. 5). In order to minimize the size of the aggregated MWCNTs, they were first dispersed in water by means of an ultrasonic probe for four hours, prior to cement and sand additions. Moreover, a superlasticizer (Mapei, Dynamon SP1) and a viscosity modifying agent (VMA, Mapei, Viscofluid SCC/10) have been added to the mixture during the stirring stage, to help increasing cohesion and homogeneity of concrete mixture and also to avoid segregation and bleeding phenomena. Both were added in amounts recommended for self-compacting concrete (SCC) preparation, for carbon nanotubes content up to $1.75 \mathrm{wt} \%$ with respect to cement. While, for higher CNTs amount, the superplasticizer content was increased to favor CNTs dispersion (Tab. 2).

The mortars showed only a slight increase of tensile strength, determined from "brazilian" tests, for a $2 \mathrm{wt} \%$ addition of pristine carbon nanotubes (Fig. 6) with respect to reference samples [26]. These results seem to indicate that the nanotubes are well dispersed within the cement matrix, but are weakly or not linked to it, as illustrated by Fig. 4, where 
after rupture of the cement matrix, the nanotubes, when visible, are rather clean and quite not recovered by cement hydration products.

\begin{tabular}{lc}
\hline Property & MWCNTs \\
Average diameter $[\mathrm{nm}]$ & $40-80$ \\
Length (average) $[\mu \mathrm{m}]$ & $400-1000$ \\
Carbon Purity $[\% \mathrm{w} / \mathrm{w}]$ & $>92$ \\
Metal Oxide (impurity) $[\% \mathrm{w} / \mathrm{w}]$ & $<6$ \\
\hline
\end{tabular}

Table 1: Features of the MWCNTs dispersed in the cement

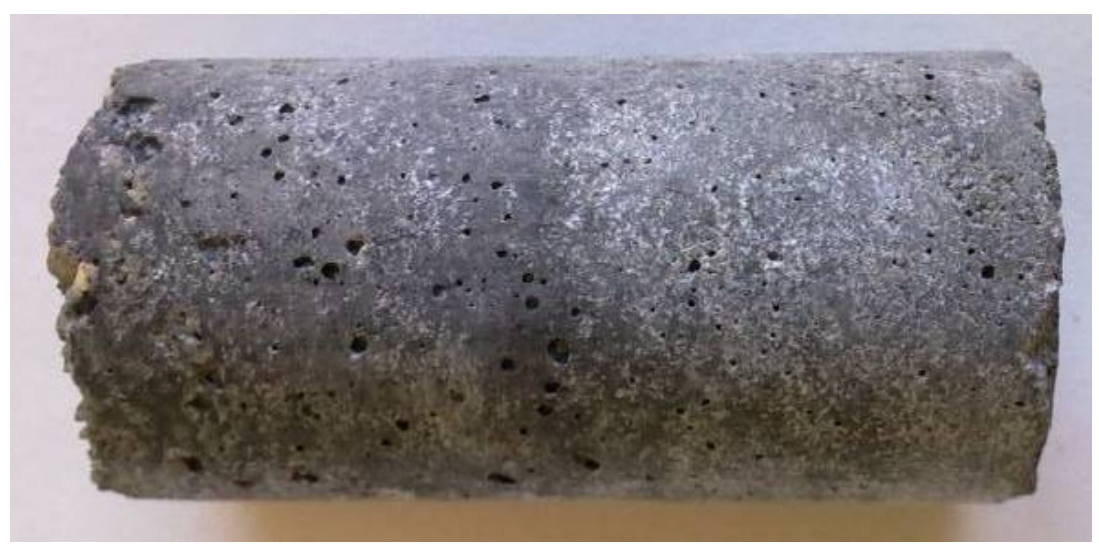

Figure 5: Mortar containing $5 \mathrm{wt} \%$ MWCNTs with respect to cement (cylinder is $4 \mathrm{~cm}$ in height and has a diameter of $2 \mathrm{~cm}$ ).

\begin{tabular}{|c|c|c|c|c|c|}
\hline \multirow[t]{2}{*}{ Components } & \multicolumn{2}{|l|}{$\begin{array}{c}\text { Reference } \\
\text { mortar }\end{array}$} & \multicolumn{2}{|c|}{$\begin{array}{l}\text { Mortars }+ \\
\text { MWCNTs }\end{array}$} & \\
\hline & \multicolumn{5}{|c|}{ Cement: CEM II A-LL (EN 197/1 standard) } \\
\hline \multicolumn{6}{|c|}{ Water to cement ratio $(\mathrm{w} / \mathrm{c}): 0.50$} \\
\hline \multicolumn{6}{|c|}{ Sand: normalized (EN 196-1 standard) } \\
\hline $\begin{array}{c}\text { Superplasticizer } \\
(\mathrm{wt} \% \text { with respect to cement) }\end{array}$ & 1.1 & 1.1 & 2 & 5 & 10 \\
\hline $\operatorname{VMA}(\mathrm{wt} \%$ / cement $)$ & 0.5 & 0.5 & 0.5 & 0.5 & 1 \\
\hline MWCNT (wt\% / cement) & 0 & $\begin{array}{l}0.5,0.75,1 \\
1.25,1.5 \text { and } \\
1.75\end{array}$ & 2 & 5 & 10 \\
\hline
\end{tabular}

Table 2: Mix-design of the prepared samples.

According to the mix-design of the different mortars reported in Tab. 2, prisms of $40 \times 40 \times 160 \mathrm{~mm}^{3}$ having $0.5 \mathrm{wt} \%$ of MWCNTs, as well as without carbon nanotubes, were also prepared for flexural tests. The results revealed that the addition of CNTs led to a significant increase of the mechanical strength, whatever the curing time, as reported in Tab. 3. 
On each half part of the former prisms, compressive tests have been also performed (Fig. 7). The observation of these stress-strain curves (Figs. 8-9) reveals that after 1 and 7 days of curing, the specimens containing MWCNTs reach the maximum compressive strength, and in general, the addition of carbon nanotubes to the cement matrix improves the mechanical performance of the samples in the early stages of maturation.

The dissipated energy density (S) can be evaluated considering the area under the curve $\sigma-\varepsilon$, and is equal to:

$$
\mathrm{S}=\mathrm{W} / \mathrm{V}
$$

where $\mathrm{W}$ is the external work $\mathrm{W}$ and $\mathrm{V}$, the sample volume.

\begin{tabular}{|c|c|c|}
\hline $\begin{array}{c}\text { Sample } \\
\text { Curing time }\end{array}$ & $\begin{array}{c}\text { Mortar as such } \\
\text { (MPa) }\end{array}$ & $\begin{array}{c}\text { Mortar }+0.5 w t \% M W C N T s \\
\text { (MPa) }\end{array}$ \\
\hline 1 day & 2.49 & 3.81 \\
\hline 7 days & 6.86 & 7.79 \\
\hline 28 days & 7.73 & 10.08 \\
\hline
\end{tabular}

Table 3: Flexural strength of $40 \times 40 \times 160 \mathrm{~mm}^{3}$ prisms in function of curing time.

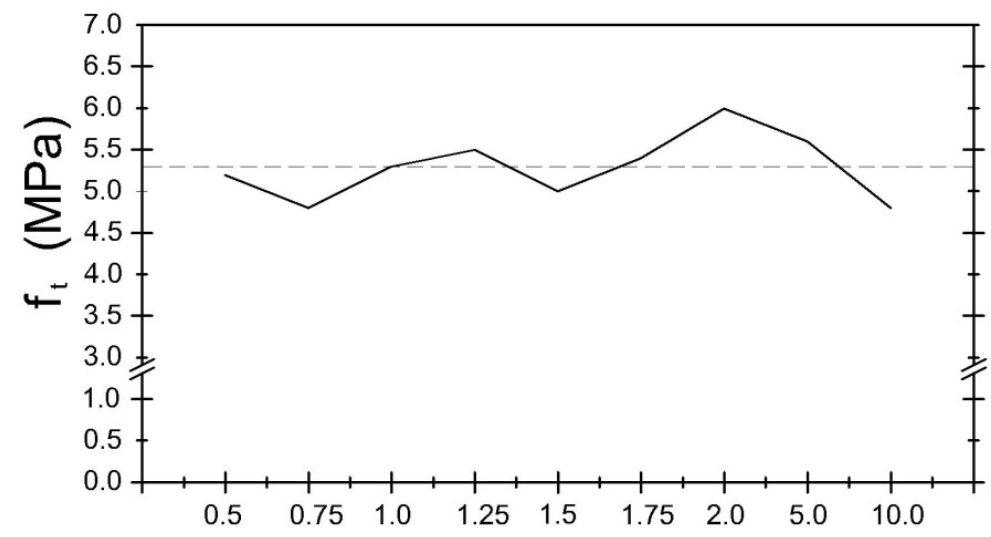

\section{MWCNTs contents (wt\%)}

Figure 6: Indirect tensile strength (from "brazilian" tests) in function of CNTs content after 7 days of curing (dashed line represents mechanical strength of samples without carbon nanotubes).

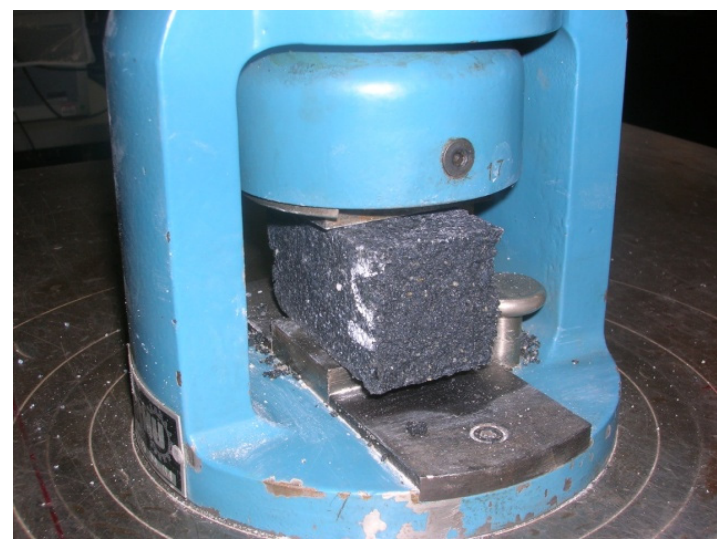

Figure 7: Compressive test on part of the sample coming from flexural test. 


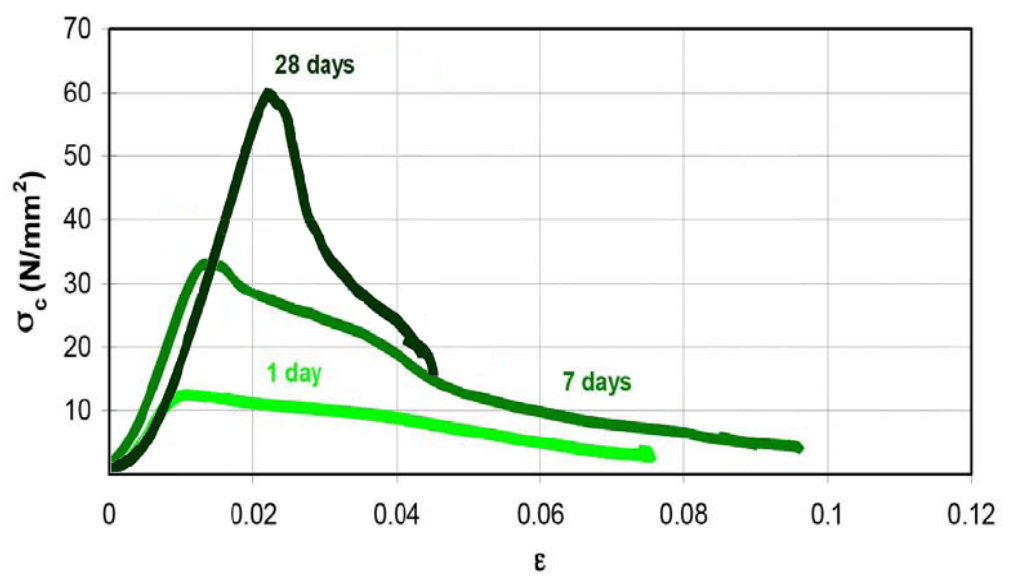

Figure 8: Comparison between $\sigma-\varepsilon$ curves of reference mortar in function of the curing days (1, 7, and 28 days).

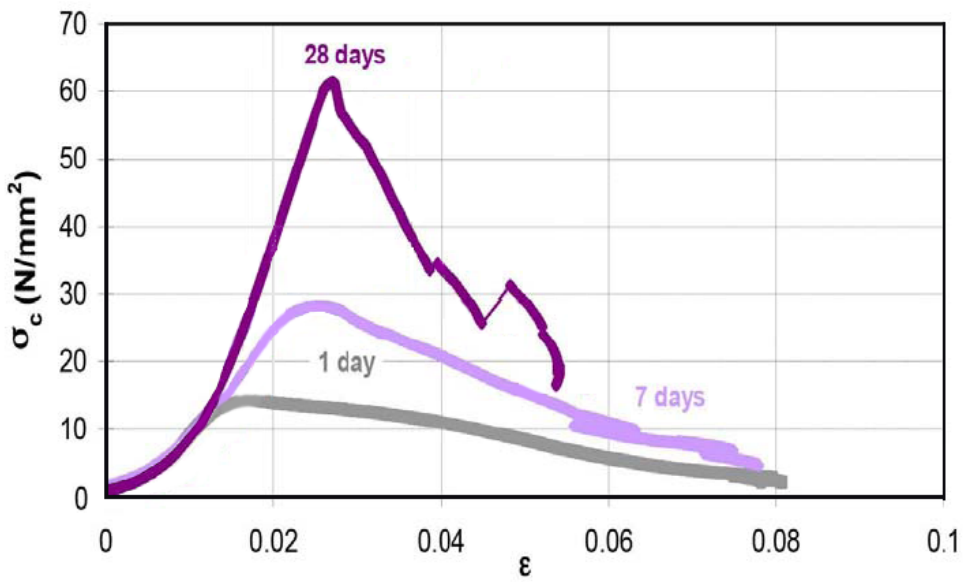

Figure 9: Comparison between $\sigma-\varepsilon$ curves of $0.5 \mathrm{wt} \%$ CNT mortar in function of the curing days $(1,7$, and 28 days).

The evolution of the dissipated energy in function of the curing days (Fig. 10) shows that after one day, the samples containing MWCNTs present the highest values of S; these values are about $50 \%$ higher respect to the reference mortar. After 7 and 28 days, the trend remains the same, albeit increasing in a smaller percentage for the samples with MWCNTs.

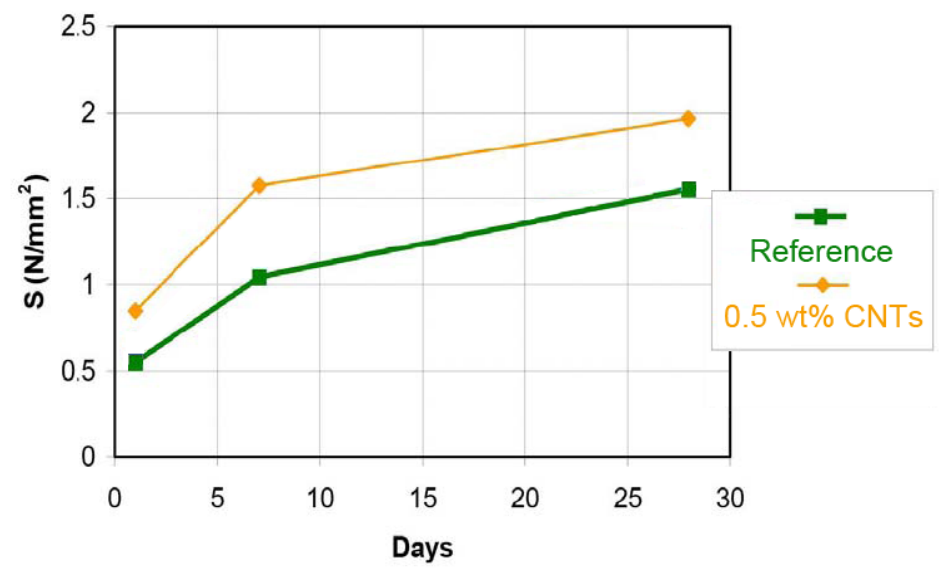

Figure 10: Mean dissipated energy in function of the curing days.

Saez de Ibarra et al. added both MWCNTs ( 0.1 and $0.2 \mathrm{wt} \%$ with respect to cement) or SWCNTs $(0.05$ and $0.1 \mathrm{wt} \%$ with respect to cement) to cement paste with gum Arabic (a water-soluble gum used as a dispersing agent) and observed an increase of the Young' modulus and hardness, as determined by nanoindentation measurements [6]. 
The interface adhesion can be improved by chemically functionalizing the nanotubes surfaces; this generates strong covalent-type of bonding [13]. Thus, the bonding between nanotubes and cement paste allows the strain to be transferred from one stage to another and crack bridging becomes effective.

It is known in the literature that carbon nanotubes treated by using a $\mathrm{H}_{2} \mathrm{SO}_{4}$ and $\mathrm{HNO}_{3}$ mixture solution (3:1 by volume, respectively) at room temperature and under ultrasonication may lead to the formation of carboxyl acid groups on their surfaces (COOH-MWCNTs). Li et al. [27] reported that carboxylic groups are effective in increasing the compressive strength up to $19 \%$, while the flexural strength increases up to $25 \%$, after addition of $0.5 \mathrm{wt} \%$ of COOH-MWCNTs [13]. Due to the presence of carboxylic acid groups on the surfaces of carbon nanotubes when modified by using the mixed solution of sulfuric acid and nitric acid, chemical reactions take place between the carboxylic acid and the calcium silicate hydrate (C-S-H) or $\mathrm{Ca}(\mathrm{OH})_{2}$ (Fig. 11).

However, it seems that the number of carboxylic groups attached to the surface of carbon nanotubes is crucial. Musso et al. have evidenced that the flexural strength of prisms $\left(40 \times 40 \times 160 \mathrm{~mm}^{3}\right)$ was divided by a factor of 2.5 with respect to the plain cement (Fig. 12), after addition of $0.5 \mathrm{wt} \%$ (with respect to the cement) of MWCNTs with $4 \mathrm{wt} \%$ of $-\mathrm{COOH}$ groups [17]. As described into the literature [28], oxidative acid treatment can strongly increase the CNTs wettability. As a consequence, depending also on the diameter of the hollow cavity, functionalized CNTs can strongly suck inside aqueous solutions by means of capillarity behavior favored by hydrophilic character [29]. As confirmed by the analysis performed on COOH-MWCNTs used to produce concrete-composite, the high amount of lattice defects and carboxylic groups can justify a strong hydrophilic behavior (Fig. 13) that is probably responsible for the incomplete hydration of cement paste added with nanotubes which initially retained the water during concrete preparation and then released it progressively during air curing.

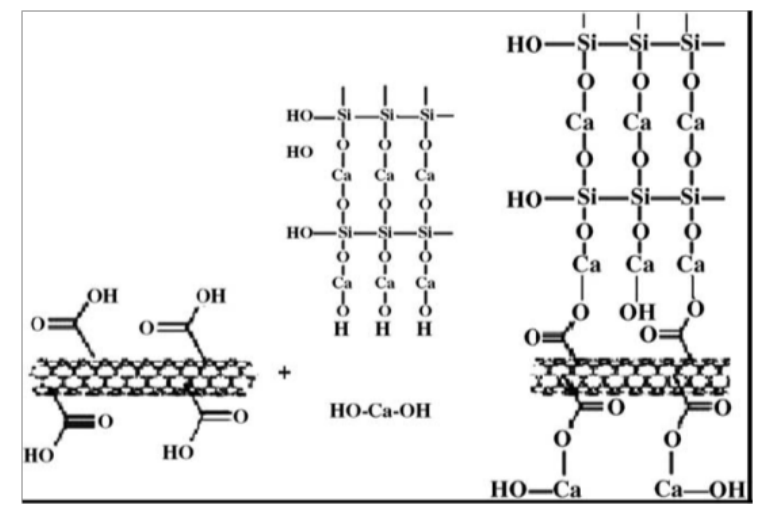

Figure 11: Reaction scheme between carboxylated nanotube and hydrated phases of cement $\left(\mathrm{Ca}(\mathrm{OH})_{2}\right.$ and $\left.\mathrm{C}-\mathrm{S}-\mathrm{H}\right)$ [13].

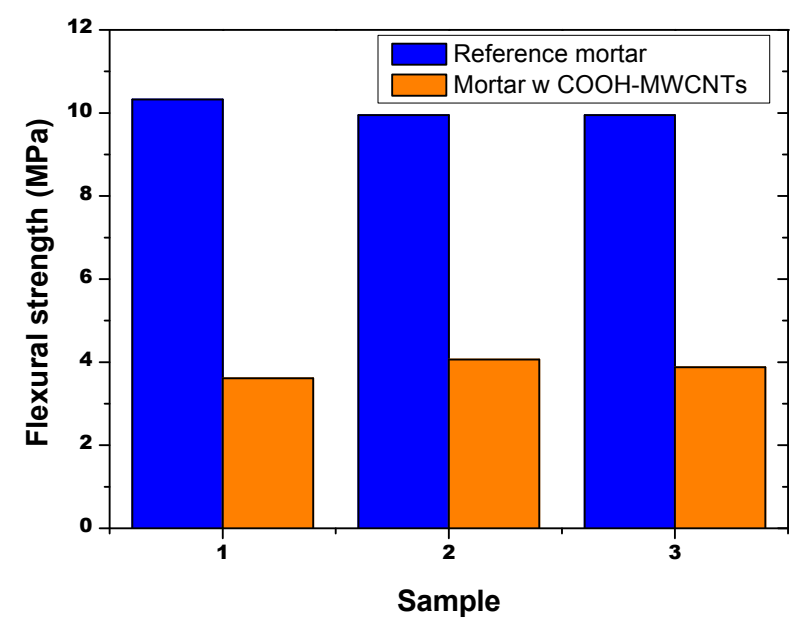

Figure 12: Flexural strength of mortars as such and with $0.5 \mathrm{wt} \%$ of COOH-MWCNTs [17] 


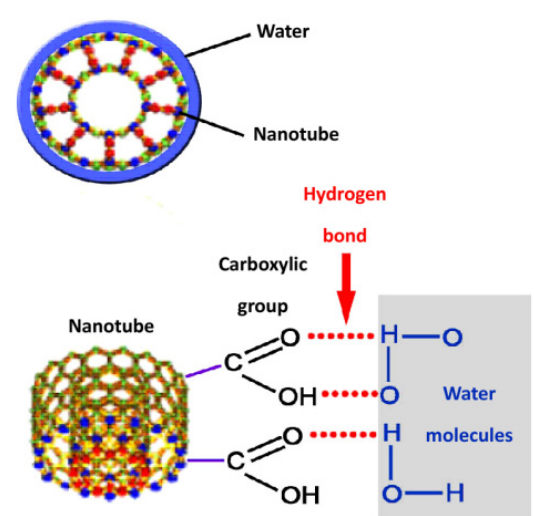

Figure 13: Possible interaction between COOH-MWCNTs and water molecules during cement hydration process [17].

\section{CNTS IDEAL CONTENT}

hah et al. [20] found that, after dispersion in water using surfactant and ultrasonic energy, small amounts of CNTs ( 0.048 wt. $\%$ and 0.08 wt. $\%$ ) produced a significant $(50 \%)$ increase in the Young's modulus of cement pastes (Fig. $14)$.

Further investigation using nanoindentation found that $\mathrm{CNTs}$ modified the $\mathrm{C}-\mathrm{S}-\mathrm{H}$, increasing the quantity of high stiffness $\mathrm{C}-\mathrm{S}-\mathrm{H}$, reinforcing the cement paste matrix at the nanoscale, and decreasing the porosity [21, 26]. Fig. 15 indicates the ideal carbon nanotubes content in function of their aspect ratio.

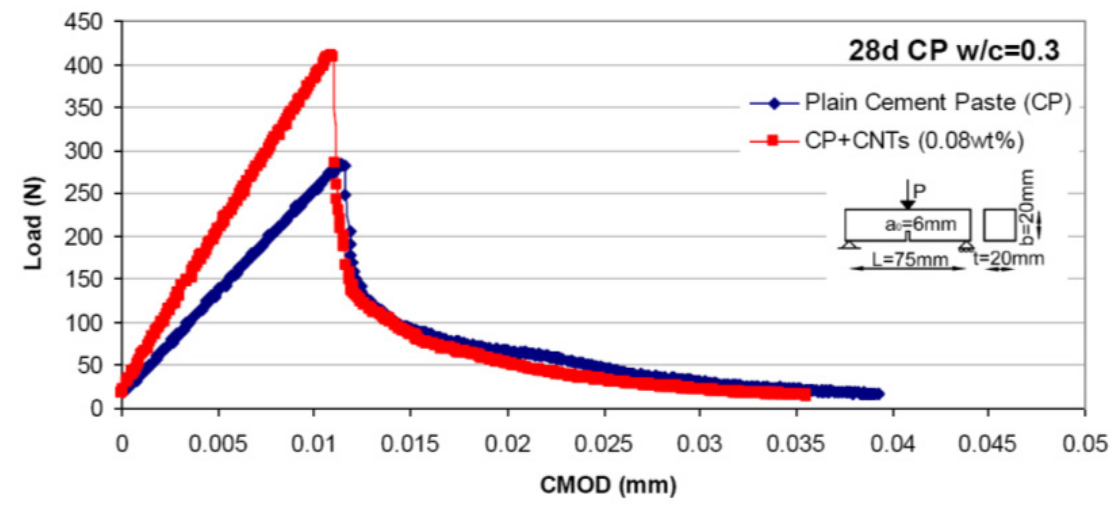

Figure 14: Flexural behaviour of cement paste with $0.08 \mathrm{wt} \%$ MWCNTs and plain cement paste.

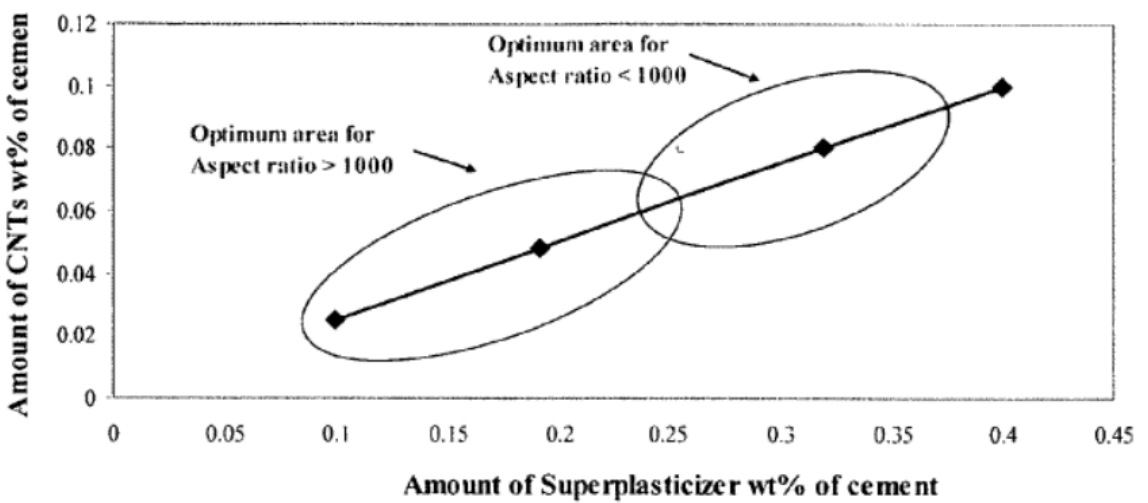

Figure 15: Optimum amount of MWCNTs and superplasticizer according to the aspect ratio of CNTs for reinforcement in cement based materials [30]. 
Saez de Ibarra et al. [10], after addition of MWCNTs or SWCNTs to cement paste with gum Arabic, observed an higher change in the samples with SWNTs, as a result of their superior mechanical properties when properly dispersed and of the lower quantity of SWNTs and gum arabic in the mix, indicating that the mix design is closer to an optimum value.

\section{SENSING PROPERTIES}

A s such carbon nanotubes can be used to decrease the electrical resistivity of cement composites by the formation of a well meshwork, while, $\mathrm{COOH}-\mathrm{MWCNT}$ s have a stronger effect on enhancing pressure-sensitive properties because they were covered by C-S-H and no meshwork was formed [27]. This latter microscopic characteristic leads to the fact that the contact points and distance among nanotubes noticeably changes with the variation of a compressive force, as illustrated by Fig. 16, where the relationship of resistivity along stress for untreated CNTs (PCNT) was 10\%, and the fractional change of resistivity for treated CNTs (SPCNT) was about 14\%. Similar results have been reported by Gao et al on carbon nanofibers (CNF) [31].

Coppola et al [15] have also shown that in the absence of an external applied force, the increase of nanotubes content in the cement paste leads to a decrease of the electrical resistance and that for $10 \mathrm{wt} \%$ of carbon nanotubes in the cement paste the sample becomes a good conductor. Moreover, they observed that capillary pores, when containing water, are the preferential paths for current, thus leading to a minor variation of the resistance under load because of a minor effect due to the carbon nanotubes.

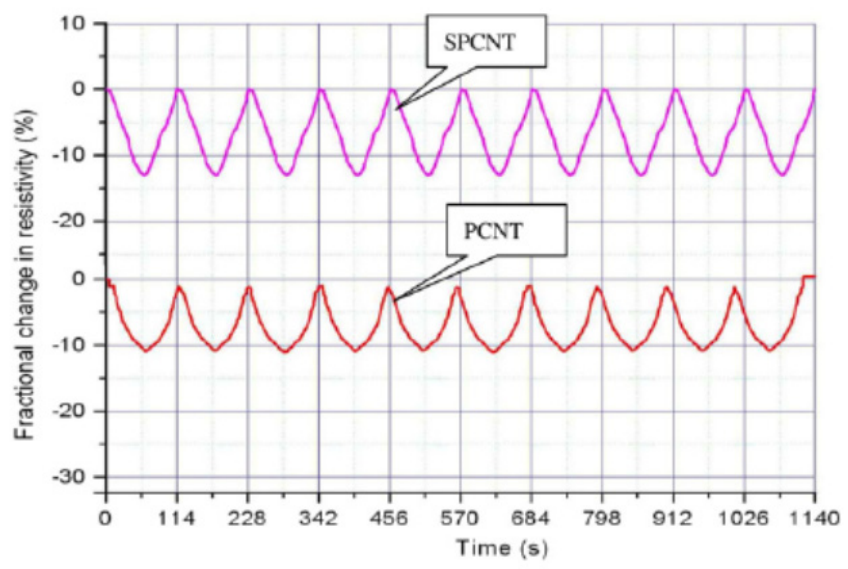

Figure 16: Fractional change in resistivity in function of time under cyclic compressive loading $(0-15 \mathrm{kN})$ on $40 \times 40 \times 160 \mathrm{~mm} \mathrm{prisms}^{3}$ (PCNT: untreated CNTs, SPCNT: treated CNTs, $0.5 \mathrm{wt} \% /$ cement) [27].

\section{CONCLUSIONS}

7 he present paper reviews the current state of the art of carbon nanotubes cement-based composites. The potential of nanotechnology to improve the performance of concrete and to lead to the development of novel, sustainable, advanced cement-based composites with unique mechanical and electrical properties is really promising. However, current challenges need to be solved before the full potential of nanotechnology can be exploited in concrete: in particular, proper dispersion and functionalization of MWCNTs, concrete processing, handling issues of CNTs, scale-up and materials cost.

\section{REFERENCES}

[1] O. Breuer, U. Sundararaj, Polymer Composites, 25 (6) (2004) 630.

[2] J. Makar, J. Margeson, J. Luh, In: $3^{\text {rd }}$ International Conference on Construction Materials: Performance, Innovations and Structural Implications, Vancouver, B.C., (2005) 1. 
[3] C.A. Hendriks, E Worrell, D. de Jager, K. Blok, P. Riemer, Emission Reduction of Greenhouse Gases from the Cement Industry, (2004), available on-line: http://www.wbcsdcement.org/pdf/tf1/prghgt42.pdf.

[4] F. Ridi, E. Fratini, P. Baglioni, Cement: A two thousand year old nano-colloid, Journal of Colloid and Interface Science, 357 (2011) 255.

[5] W.D. Jones, How to build a mile-high skyscraper, IEEE Spectrum, june 2007, available on-line: http://spectrum.ieee.org/energy/environment/how-to-build-a-milehigh-skyscraper.

[6] K. Eguchi, K. Teranishi, A. Nakagome, H. Kishimoto, K. Shinozaki, M. Narikawal, Application of recycled coarse aggregate by mixture to concrete construction, Construction and Building Materials, 21 (2007) 1542.

[7] E.T. Thostenson, Z. Ren, T.W. Chou, Composites Science and Technology, 61 (2001) 1899.

[8] R. Andrews, D. Jacques, D. Qian, E.C. Dickey, Carbon, 39 (2001) 1681.

[9] S. Musso, M. Giorcelli, M. Pavese, S. Bianco, M. Rovere, A. Tagliaferro, Diamond and Related Materials, 17 (2008) 542.

[10] Y. Saez de Ibarra, J.J. Gaitero, E. Erkizia, I. Campillo, Physica Status Solidi, 203(6) (2006) 1076.

[11] S. Musso, S. Porro, M. Vinante, L. Vanzetti, R. Ploeger, M. Giorcelli, B. Possetti, F. Trotta, C. Pederzolli, A. Tagliaferro, Diamond and Related Materials, 16 (2007) 1183.

[12] S. Osswald, M. Havel, Y. Gogotsi, Journal of Raman Spectroscopy, 38(6) (2007) 728.

[13] G.Y. Li, P.M. Wang, X. Zhao, Carbon, 43 (2005) 1239.

[14] L. Valentini, I. Armentano, L. Lozzi, S. Santucci and J. M. Kenny, Materials Science and Engineering C 24 (2004) 527.

[15] L. Coppola, A. Buoso, F. Corazza, Enco Journal, 51 (2010) available on-line: http://www.enco-journal.com/journal/ ej51/coppola.html

[16] B. Han, X. Yu, E. Kwon, Nanotechnology, 20, (2009) 445501.

[17] S. Musso, J.M. Tulliani, G. Ferro, A. Tagliaferro, Composites Science and Technology, 69 (2009) 1985.

[18] Y.-H. Liao, O. Marietta-Tondin, Z. Liang, C. Zhang, B. Wang, Materials Science and Engineering A 385, (2004) 175.

[19] Canepa F., Ferro G., Tulliani J.M, Cauda V., In: Atti del $19^{\circ}$ Convegno Nazionale del Gruppo Italiano Frattura (IGF), Milano, Italy, 2007, 369-377.

[20] S. Musso, J.M. Tulliani, A. Tagliaferro, G. Ferro, In: Proceedings of the $12^{\text {th }}$ International Conference on Fracture (ICF), Ottawa, Canada, 2009, CD-ROM, Paper N. 937.

[21] G. Ferro, J.M. Tulliani, S. Musso, A. Tagliaferro, In: Proceedings of the 17th European Conference on Fracture (ECF), Brno, Czech Republic, 2008, CD-ROM, Paper N. CE170500

[22] M. Ipperico, G. Ferro, S. Musso, J.M. Tulliani, A. Tagliaferro, In: Atti del $20^{\circ}$ Convegno Nazionale del Gruppo Italiano Frattura (IGF), Torino, Italy, 2009, 103-112.

[23] M. S. Konsta-Gdoutos, Z.S. Metaxa, S.P. Shah, Cement and Concrete Research, 40 (7) (2010) 1052

[24] S.P. Shah, J.H. Kim, N. Tregger, Z. Metaxa, In: Proceedings of the Indian Concrete Institute Asian Conference on Ecstasy in Concrete, Chennai (India), (2010).

[25] M. S. Konsta-Gdoutos, Z.S. Metaxa, S.P. Shah, Cement and Concrete Composites, 32 (2) (2010) 110.

[26] J.-M. Tulliani, S. Musso, J.-P. Lecompte, G. Ferro, In: Proceedings of ICRACM-2010 - $3^{\text {rd }}$ International Conference on Recent Advances in Composite Materials, Limoges (France), (2010).

[27] G.Y. Li, P.M. Wang, X. Zhao, Cement \& Concrete Composites, 29 (2007) 377.

[28] P.M. Ajayan, S. Iijima, Nature, 361 (1993), 333.

[29] O. Ersen, J. Werckmann, M. Houlle, M.J. Ledoux and C. Pham-Huu, Nano Letters, 7 (7) (2007) 1898.

[30] S.P. Shah, M. S. Konsta-Gdoutos, Z.S. Metaxa, Highly dispersed carbon nanotube-reinforced cement-based materials, US Patent 2009/0229494A1, (2009).

[31] D. Gao, M. Sturm, Y. L. Mo, Smart Materials and Structures, 18 (2009) 1. 